\title{
Infectious Coryza in Jimma Backyard Chicken Farms: Clinical and Bacteriological Investigation
}

lyasu Angani Dereja* and Dagnachew Hailemichael

Animal Products, Veterinary Drug and Feed Quality Assessment Center, Addis Ababa, Ethiopia

\begin{abstract}
A cross sectional study on infectious coryza was conducted in Jimma, Ethiopia, from November 2011 to April 2012 with the objectives of determining the prevalence of infectious coryza, and associated factors. A total of 456 specimens from chicken were processed and the overall infection prevalence was $22.4 \%$. From animal related risk factors considered, breed and age were found to be risk factors. Isolation of the agent, Avibacterium paragallinarum in exotic and cross breeds were highly statistically significant compared to local breeds (odds ratio $=3.890$, $P$-value $=0.000$ and odds ratio $=2.282$, $P$-value $=0.010$, respectively). The highest incidence was observed January to April. Swab specimens revealed more infection (27.1\%) than fecal samples $(18.9 \%)$ suggesting the disease is more respiratory than it is digestive or systemic. Though clinically ill ones, there were numerous chickens with the infection without showing any sign of the disease. Based on these findings, keeping the genetic potential of the local breed poultry while upgrading their productive potential is recommended as a best method to control the infection.
\end{abstract}

Keywords: Avibacterium paragallinarum; Backyard; Infectious coryza; Isolation; Jimma

Abbreviations: A. paragallinarum: Avibacterium paragallinarum; CI: Confidence interval; DF: Degree of freedom; IC: Infectious coryza; JUCAVM: Jimma University College of Agriculture and Veterinary Medicine; NAD: Nicotinamide adenine dinucleotide; OR: Odds ratio; SPSS: Statistical package for social science; URT: Upper respiratory tract.

\section{Introduction}

Chicken production promises considerable potential to improve livelihood of rapidly increasing populations of developing countries. For many poor people in these countries, chickens are the only type of livestock they can afford to keep, which are relatively risk free [1]. With an estimated $60 \%$ of the total chicken population in East Africa, Ethiopia has an around 45 million heads. Of the national flock, the local breeds represent $98 \%$ [2].

Despite this huge population of poultry, the industry in the country remains highly undeveloped due to many constraints of which one is diseases. Although it is understood that diseases cause great losses, many of them are unstudied. Infectious coryza is one of such poultry catastrophes. Because many countries having trade relation with it have reported losses, it is rational argument that studies should be conducted to determine the status of the infection in Ethiopia. This study was therefore, conducted in the city of Jimma with the objectives of: Determining the prevalence of the disease in the study area, using clinical and bacteriological inquiries; and

Showing associated factors in the study area.

\section{Literature Review}

\section{Infectious coryza}

Infectious coryza is a disease caused by a bacterium Avibacterium paragallinarum (previously Haemophilus paragallinarum). It is an acute to chronic respiratory disease of chickens. However, there are some experts that believe the disease also has digestive system or systemic nature. It is mainly observed in pullets and layers, and occasionally broilers [3-5].
The disease was named infectious coryza because it was infectious and affected primarily the nasal passage. The clinical syndromes have been described in the early times as roup, contagious catarrh, cold and uncomplicated coryza. Infectious coryza is characterized by conjunctivitis, catarrhal inflammation of the URT (upper respiratory tract), sneezing, swelling of the face under the eyes, and reduction in egg production.

\section{Etiology}

Avibacterium paragallinarum is a causative agent for Infectious coryza (IC). It was previously known as Haemophilus paragallinarum. It is from the genus Haemophilus, which is a member of the family Pasteurellaceae. The family is known for its pleomorphic, gram negative, non-motile, bacilli and coccobacilli organisms that are able to reduce nitrates and utilize carbohydrates. As many species in the genus, A. paragallinarum is catalase negative microaerophilic rod $[3,6]$.

\section{Epidemiology}

The disease occurrence is worldwide. It was reported from Argentina, Australia, Germany, India, Indonesia, Japan, Malaysia, Mexico, Morocco, Pakistan, Taiwan, Thailand, the Americas and Uganda [7-11]. Chickens of all age group are susceptible, yet susceptibility increases with age. Some studies show that susceptibility increases four weeks post hatching. Thus, multiage farms tend to preserve the disease $[3,12]$.

*Corresponding author: Iyasu Angani Dereja, Animal Products, Veterinary Drug and Feed Quality Assessment Center, Addis Ababa, Ethiopia, Tel: +251910869263; E-mail: iyasuangani@uopeople.edu

Received November 29, 2016; Accepted Janauray 10, 2017; Published Janauray 12, 2017

Citation: Dereja IA, Hailemichael D (2017) Infectious Coryza in Jimma Backyard Chicken Farms: Clinical and Bacteriological Investigation. J Vet Sci Technol 8: 412. doi: 10.4172/2157-7579.1000412

Copyright: ( 2017 Dereja IA, et al. This is an open-access article distributed under the terms of the Creative Commons Attribution License, which permits unrestricted use, distribution, and reproduction in any medium, provided the original author and source are credited. 


\section{Physicochemical property}

The Haemophilus group of bacteria is a heterogeneous group of small, gram negative, aerobic, bacilli, non-motile, non-spore forming and which require enriched media which include $\mathrm{V}$-factor/ nicotinamide adenine dinucleotide (NAD). However, there are some isolates of $A$. paragallinarum that do not need NAD. Some scholars prefer in other hand 5\% sheep blood agar as the most universally used isolation medium for A. paragallinarum. The bacterium doesn't grow on standard media used in antimicrobial sensitivity testing; it grows with supplement Muller Hinton agar which is capable of supporting the growth of $A$. paragallinarum. The minimal and maximal temperatures for the growth of the bacterium are 37 and $38^{\circ} \mathrm{C}$. It is able to produce acid from maltose, mannitol, sorbitol and sucrose $[4,13,14]$.

\section{Serological variations}

Two classification systems applied to A. paragallinarum are the "Page" and the "Kume" methods. Based on the first method, which employed the use of the plate agglutination method, three different serotypes termed A, B and C was detected. On the other hand, the Kume method is based on hemagglutination. Accordingly, three different serogroups I, II and III consisting of seven serovars (HA-1 to HA-7) were detected. Kume's serogroups I, II and III correspond to Page's serovars A, C and B respectively. This subsequently led towards the proposal to alter the Kume scheme nomenclature concluding with the nine currently recognized serovars [15-17]. Studies indicated that $A$ and $C$ are the pathogenic serovars of the bacterium whereas $B$ is not clearly understood regarding its pathogenicity. Yet, Yamaguchi et al. [18] reported that the serovar is pathogenic, in Argentina [10,19,20].

\section{Transmission}

Bird to bird is the most recognized transmission way of the disease. However, contaminated feed and water is also mode of blowout, most probably in case of outbreaks in flocks. It spreads mainly through clinically affected and carrier birds. Birds that have recovered from field infection are said to be immune to reinfection at least for a year. Bird to bird transmission is via respiratory rout or by contact with contaminated drinking water [5,12,21-24].

\section{Pathogenesis}

The initial step in the pathogenesis of infectious coryza is adherence to and colonization of the nasal mucosa. A polysaccharide capsule of $A$. paragallinarum mediates its attachment to the cilia of the nasal mucosa. The lipopolysaccharide (LPS) in the cell wall and hyaluronic acid component of these capsules are believed to contribute to pathogenesis although these interactions of the host have not been clearly defined. A belief from other scholars is that endotoxin play a role in the pathogenesis. Still, virulence factures haven't been fully identified. Some others still believe that outer membrane proteins of the agent are of potential as virulence determinants. Studies report that secreted proteins of $A$. paragallinarum are lethal for chicken embryo [12,25-27].

\section{Incubation period, clinical signs, and morbidity and mortality}

The incubation period of IC varies 24 to 48 hours after experimental inoculation of the organism. However, it may depend on particular exposure from 24 hours by intrasinusal inoculation to 14 days by air born transmission $[9,28]$. A characteristic swelling of the infraorbital region, oculonasal discharge, swollen wattles, diarrhea and inappetence are common clinical signs. Losses are due to decreased feed consumption which impacts meat and egg yield. Some other unusual clinical presentations are arthritis and septicemia.

In the mildest form, depression, nasal discharge and occasional slight facial swelling may be the only signs. In the sever form, there is a server swelling of one or both infraorbital tissues with edema of the surrounding tissues, which may close one or both eyes. This edema may extend to the wattles and the inter-mandibular spaces. The swelling usually subsides in 10-40 days. Still, it may persist for months in complicated cases $[3,12]$. Clinically, IC is usually characterized by high morbidity rates. Losses due to persistent mortality are culling where up to $5 \%$. Affected flocks may suffer an egg drop of up to $10 \%$, and to $100 \%$ in more serious situations [29-32].

\section{Post mortem lesions and histopathology}

Whereas lesions may be limited to the infraorbital sinuses in acute cases, other complicated signs may be observed in chronic ones. The lesions may include yellowish sinus exudate, conjunctivitis, thracheitis, and bronchitis. Upon postmortem, affected birds show increased mucus and necrotic debris in the trachea. There is also infraorbital swelling escorted by congestion of mucus membrane of the nasal cavity and sinuses. Sometimes, there may be lung edema and opacity, and congealing of the abdominal air sacs. Upon histological examination of the URT, there are usually lesions ranging from necrosis of the respiratory epithelium to marked hypoplasia and squamous metaplasia of the sinuses $[3,12,23,33]$.

\section{Diagnostic techniques}

Although the history and the clinical signs can be suggestive, they are neither confirmative nor pathognomonic. In a certain study [34], $46 \%$ of chickens which finally found to be positive to many other diseases showed signs similar to that of IC. Therefore, laboratory investigations including bacteriology are required to demonstrate the presence of the causative agent [35]. Chocolate agar or blood agar inoculated with a streak of Staphylococcus aurous, incubated at $37^{\circ} \mathrm{C}$ for 2-3 days in moist atmosphere, is used for isolation.

\section{Prevention and control}

Prevention is the only sound method of control. Improved management aspects including hygiene, housing, flock structure and young chick care and others are most economical and effective means of prevention. Hygienic measures include frequent turning and changing of poultry liter, frequent clearing of feeders and drinkers, and regular disinfection of poultry houses. Whereas, housing measures include ventilation, quarantine of new entries, and proper spacing. Replacements should be raised on the same farm or obtained from clean flocks. Segregation of birds by age is also another remarkable measure that can be applied especially in outbreak cases [12,34].

Bacterins are available to prevent and control the disease. Early vaccination is also useful method of prevention. All replacement birds on endemic farms should be vaccinated $[19,25]$. A killed vaccine containing serovars A and C have been developed. Yet, outbreaks have been reported in vaccinated flocks in several countries, suggesting the existing new serotypes $[3,16,34,36,37]$.

\section{Treatment}

Because early treatment is necessary, water medication is recommended. Many drugs have bacteriostatic effect on the organism. Erythromycin, Tetracycline, Fluoroquinolones, Sulphadimetoxine, and Sulphamethazine can be used as treatment medication. Although 
treatment may result in improvement, the disease may recur when medication is discontinued [3,12,21-24,38]

\section{Materials and Methods}

\section{The study area}

The study was conducted from November 2011 to April 2012 in Jimma town, which is located about $375 \mathrm{Km}$ from Addis Ababa, the capital city of Ethiopia. It is positioned at latitude of about $7^{\circ} 13^{\prime}$ to $8^{\circ} 56^{\prime} \mathrm{N}$ and longitudes of about $35^{\circ} 52^{\prime}$ to $37^{\circ} 37^{\prime} \mathrm{E}$. The area receives a mean annual rainfall of about 1530 milliliters with bimodal rainfall. The minimum and maximum annual temperatures are $7^{\circ} \mathrm{C}$ and $30^{\circ} \mathrm{C}$, respectively. Jimma has a livestock population of about 4,540,311 of which $1,139,735(25.10 \%)$ are poultry.

\section{The study population}

The study elements were backyard chickens from selected kebeles of Jimma town. The study was carried out on all ages of both sexes from three breeds (Pure local, cross, and pure exotic) and two management systems (backyard extensive and backyard intensive).

\section{Study design}

The study was cross-sectional experimental to isolate $A$. paragallinarum both in clinically ill and non-clinical backyard chickens in the study area. It was conducted in five randomly selected kebeles of Jimma town.

\section{Sampling and sample size determination}

The households with backyard chicken production were selected by simple random sampling technique until the desired sample size was met. The sample size was determined using the formula of Thrusfield [35]. Based on this formula and considering 95\% confidence level, $5 \%$ desired absolute precision and $50 \%$ expected prevalence, the sample size was 384 . Yet, to increase the accuracy of representation, it has been increased to 456 .

$$
n=\frac{(1.96)^{2} p_{\exp }\left(1-p_{e} x p\right)}{d^{2}}
$$

Where $\mathrm{n}=$ Required sample size, $\mathrm{P}_{\exp }=$ Expected prevalence and $\mathrm{d}=$ Desired absolute precision.

The study sample was comprised of 86 male and 370 female chickens of which 147 were local, 143 cross and 136 exotic breeds. 184 of the chickens were young and the rest 272 were adult (all chickens whose age are six or less were taken as young, whereas older as adult). 217 chickens from backyard extensive management system and 239 from backyard intensive management system were considered. Of this, 238 were reared for egg, 85 for meat and the rest 133 for dual reason.

\section{Study methodology}

Sample collection and transportation: Data were collected from the owners on their management system, production purpose, and age of the poultry. The data so generated was then recorded on the data recording sheet. The health status of the sampled chicken was recorded as clinically ill or healthy by general physical observation. From each study element, two types of specimens (swab from trachea and infraorbital sinus, and fecal sample from rectum) were collected for isolation of A. paragallinarum.

Sterile gloves, cotton and bottles were employed for the collection.
The bottles were then labeled with chicken identities, specimen type, date of sampling, and other notes. The pack was then transported on the date it was collected to the JUCAVM microbiology laboratory using an ice box.

Sample processing: The specimens collected were diluted with distilled water prior to isolation. Then the dilutions were cultured on a blood agar plate in which $5 \%$ sheep blood was added, and Staphylococcus aureus was streak on. After being incubated at $37^{\circ} \mathrm{C}$ for 28 hours with $5 \% \mathrm{CO}_{2}$, the plates have been sub cultured. The bacterial colonies showing satellite growth were taken as culture positive and cells from discrete colonies were picked up for Graham's and Giemsa's stains [39].

The inocula which both found gram negative and bipolar on Giemsa's stain were taken for oxidase and catalase tests while those failed even in one of the two staining techniques were rejected. Oxidase and catalase tests were done as recommendation of Salle [40]. The IC positive plates were negative for both tests. Sugar fermentation tests for sucrose, lactose and mannitol were conducted on those slides, as recommended by Gordan and Jordan [24].

Data management and analysis: The data collected on the study were processed using computer software. While Microsoft excel 2010 was used for data entry, analysis was performed using statistical data social science (SPSS) version 17 . To summarize the data, descriptive statistics such as percentage were used. The strength of association of potential risk factors (explanatory variables) to presence of infectious coryza infection (response variable) was determined by binary logistic regression using SPSS-17. For all tests p-values less than 0.05 were considered statistically significant.

\section{Results}

The causative agent of Infectious coryza, A paragallinarum, was isolated from $22.4 \%$ (95\% CI $18.57 \%, 26.23 \%$ ) of the study samples. The prevalence in swab samples $(27.1 \%)$ was 1.72 times more than the prevalence in fecal samples (18.9), which was statistically significant (Table 1).

The explanatory variables considered in this study were grouped as animal related (age, sex and breed), season and others (breeding purpose, management system and clinical illness). From animal related risk factors, breed and age were found to be risk factors for isolation of the etiology (Table 2). Isolation of the agent in exotic (32.4\%) and cross $(23.1 \%)$ breeds was highly statistically significant as compared to its local $(12.2 \%)$ equivalent $(\mathrm{OR}=3.890, \mathrm{P}=0.000$ and $\mathrm{OR}=2.282$, $\mathrm{p}=0.010$, respectively). Younger chickens were more resistant than adults $(\mathrm{OR}=2.169, \mathrm{p}=0.002)$. Males $(30.2 \%)$ were more susceptible than females $(20.5 \%)$. However not statistically significant $(\mathrm{OR}=1.529$, $\mathrm{p}=0.163)$.

The study showed that there is considerable difference on the incidence of the infection on the different months of the study period. Minimum and maximum percentages were $8.8 \%$ on November and $39.7 \%$ on March, respectively (Table 3 ).

Other factors considered in the study were management system, breeding system and clinical sickness. The result revealed that all these factors have no significant association with isolation of $A$. paragallinarum (Table 4). No outbreak occurred during the study although there were numerous chicken showing sign of coryza. Still, 
Citation: Dereja IA, Hailemichael D (2017) Infectious Coryza in Jimma Backyard Chicken Farms: Clinical and Bacteriological Investigation. J Vet Sci Technol 8: 412. doi: 10.4172/2157-7579.1000412

Page 4 of 6

\begin{tabular}{|c|c|c|c|c|}
\hline Sample type & Prevalence (\%) & $\mathbf{9 5 \%}$ Cl of prevalence & P-value & OR \\
\hline Fecal $(n=264)$ & 18.9 & $18.80-18.99$ & \\
\hline Swab $(n=192)$ & 27.1 & $26.97-27.22$ & 0.018 \\
\hline Total $(n=22.4)$ & 22.4 & $18.57-26.23$ & 1.72 & \\
\hline
\end{tabular}

Table 1: Prevalence of isolation of $A$. paragallinarum in backyard chickens of Jimma town.

\begin{tabular}{|c|c|c|c|c|c|}
\hline Factor & Category & Prevalence (\%) & P-value & OR & $95 \% \mathrm{Cl}$ of OR \\
\hline \multirow{3}{*}{ Breed } & Local & 12.2 & & & \\
\hline & Cross & 23.1 & 0.010 & 2.282 & $1.22-4.267$ \\
\hline & Exotic & 32.4 & 0.000 & 3.89 & $2.067-7.32$ \\
\hline \multirow{2}{*}{ Sex } & Female & 20.5 & & & \\
\hline & Male & 30.2 & 0.168 & 1.529 & $0.842-2.779$ \\
\hline \multirow{2}{*}{ Age } & Young & 15.2 & & & \\
\hline & Adult & 27.2 & 0.002 & 2.169 & $1.328-3.544$ \\
\hline
\end{tabular}

Table 2: Isolation of $A$. paragallinarum based on animal related risk factors.

\begin{tabular}{|c|c|c|c|}
\hline Month & Positive (\%) & DF & p-value \\
\hline November $(n=57)$ & 8.8 & & \\
\hline December $(n=95)$ & 12.6 & 5 & \\
\hline January $(n=114)$ & 21.9 & & \\
\hline February $(n=17)$ & 29.4 & & \\
\hline March $(n=73)$ & 39.7 & & \\
\hline April $(n=17)$ & 29.4 & & \\
\hline
\end{tabular}

Table 3: Occurrence of $A$. paragallinarum infection based on the time of investigation.

\begin{tabular}{|c|c|c|c|c|}
\hline Factor & Category & Prevalence (\%) & P-value & OR \\
\hline \multirow{2}{*}{ Management } & Intensive & 19.7 & & \\
\hline \multirow{3}{*}{ Purpose } & Extensive & 25.3 & 0.236 & 1.312 \\
\cline { 2 - 5 } & Dual & 22.6 & 0.531 & 1.246 \\
\hline \multirow{2}{*}{ Clinical illness } & Meat & 29.4 & & \\
\cline { 2 - 5 } & Ygg & 19.7 & & \\
\hline
\end{tabular}

Table 4: Association of poultry management system, breeding purpose and clinical illness with isolation of isolation of $A$. paragallinarum.

clinically ill birds were more likely to develop IC (32.1\%) than clinically healthy ones (21.75\%).

\section{Discussion}

Infectious coryza is highly infectious poultry disease caused by A. paragallinarum and is seen in many countries all over the world. Although there are numerous reports from neighboring countries, no evidence of previous study on the infection found in the country. As such, focus was given to its incidence and associated factors to its occurrence in the study area.

In this study, A. paragallinarum, causative agent of IC was isolated from backyard poultry farms of Jimma. It showed a total isolation prevalence of $22.4 \%$, which agrees with the report of Byarugaba et al. [41] where they found a seroprevalence of $22 \%$ in Uganda, but higher than the findings of Mustefa and Ali [42] 8.3\%, Rahman et al. [43] $0.59 \%$ and Islam et al. [44] 0.37\% occurrences in Bangladesh. These differences might have been arisen from factors such as agroecology; the tropical climate is favorable to proliferation of the microorganism $[3,45]$. The result of the present study was in line with this general fact. Disease complications are much more complicated in the study country, which help the microorganism to invade the immunity of chickens [15]. Moreover, chicken vaccination is not practiced strictly in the community; this might have increased the chance of infection of the chickens. In addition, the present work was conducted from November to April, which comprises the windy season of the year in the country which favors transmission of the agent [46].

The this result however, is much lesser than the report of Byarugaba et al. [7] in which they investigated $40.5 \%$ coryza cases and the works of Sakamato et al. [47] who reported antibody prevalence level of $80 \%$ for serovar A and $60 \%$ for serovar C on ELISA. This variation might be due to the fact that their work was on disease outbreak and may also be due to the laboratory techniques employed; unlike the present study, they used antibody detection technique where there are numerous false positives due to cross protections [48].

Infectious coryza is a known respiratory disease but it is not limited to the respiratory system. It sometimes takes systemic form and even cause diarrhea [49], which indicates that it has digestive system significance too. In the present study, the bacterium was isolated on both fecal and swab samples.

Naturally male chickens are more susceptible too A. paragallinarum than females [38]. The present study result was in line with this fat in that the prevalence was $30.2 \%$ in males and $20.5 \%$ in females. Normally a male chicken reaches numerous females than a female chicken reaches males or females reach each other. That might be why males are more vulnerable than females. 
Age wise, the disease was more common in adult birds. This is because, as the poultry gets older, the bursa of fabricius, where B lymphocytes are produced, shrinks; this weakens the humeral immunity of the hosts which intern becomes favorable to the disease causing microorganism [50]. This result agrees with the study conducted in Thailand by Thitisak et al. [50] which showed that higher proportion of infected chickens were below two months and above six months.

In this study, there was a strong association between the isolation of $A$. paragallinarum and season of the investigation in the study area. The highest incidence was observed during the months of January to April. This agrees with the report of Thitisak et al. [50] who reported the occurrence of infection during the windy months of the year. The months are in the hottest season of the year in the study area and they are also in the windy months which facilitate ease of transmission of the microorganism [51]. In addition, this is the time in which the popular holidays "Genna" and "Fasica" are celebrated and poultry are marketed more than any other time whole over the country. These active market times may contribute for the infection transmission.

Per this study, management system and breeding purpose couldn't affect the occurrence of the disease in the study populations. This might be due to irregularity of the management system in the study area. In the country, chickens are usually raised by children and females; they usually have not well proposed purpose by raising the chickens. Thus, this condition might have contributed for the difficulty to know the effect of the management on the disease's incidence.

The isolation of $A$. paragallinarum was higher in clinically ill birds $(32.1 \%)$ than clinically healthy ones $(21.7 \%)$. The greater percentage of infection on the clinically ill birds might be from immunosuppression due to complications. This indicated that not only sick ones, but also members recovered from the clinical coryza cases may harbor the disease without showing any clinical signs [12].

\section{Conclusion and Recommendations}

In summary, isolation of A. paragallinarum confirmed the presence of infectious coryza in Ethiopia. The infection was highly prevalent in the study area. The animal related factors such as breed, age and sex were observed affecting the occurrence of the infection. The disease is highly contagious and once entered the flock, it's usually a risk for the whole farm. The disease has significant economic importance which is too risky to farms, which is usually observed by drop in egg production and body condition. This intern affects the poor, which mainly comprises women and children, aggravating its effect on food security of the country.

In general, the disease may be one of the economic risks to the country unless appropriate measures are taken with the right time. But immediate and cooperated responses can reduce its effect. Thus, the following are recommended based on this conclusion:

- Public awareness creation should be performed using various intervention techniques;

- The genetic potential of indigenous chickens ought to be kept while upgrading their productivity;

- Strict biosecurity measures must be practiced in poultry farms; and

- Further researches should be done concerning the disease and associated factors as it pertains to economic and social lives in developing countries.

\section{Conflict of Interest Statement}

The authors declare that there is no conflict of interest

\section{References}

1. Tadelle D (2011) Livestock exchange: why chicken research for development? ILRI, Addis Ababa, Ethiopia.

2. Pagani $P$, Abebe $W(2008)$ Review of new features of Ethiopian poultry sector biosecurity implications. FAO, Addis Ababa.

3. Aiello E, Amstutz HE, Anderson DA, Armour IS, leffcott LB, et al. (1998) The Merck veterinary manual. 8th edn., Merck and Co Inc., New Jersey, USA.

4. Saif $Y(2003)$ Poultry diseases. 8th edn. Blackwell, Low state, USA

5. McMullin P (2004) The poultry site, Infectious Coryza.

6. Baron E, Peterson L, Fingold S (1994) Diagnostic microbiology. 9th edn Mosby.

7. Byarugaba D, Minga U, Gwakisa P, Katunguka E, Bisgaard M, et al. (2006) Occurrence, isolation and characterization of Avibacterium paragallinarum from poultry farms in Uganda. Proceedings of the $11^{\text {th }}$ international symposium on veterinary epidemiology and economics.

8. Hinz K (1973) Differentiation of Haemophilus strains isolated from chickens IV. Studies on the dissociation of Haemophilus paragallinarum. Avian Pathol 5: 51-66.

9. Kume K, Sawata A, Nakase Y (1978) Haemophilus infections in chickens 1. Characterization of Haemophilus paragallinarum isolates from chickens affected with coryza. Japanese J Vet Sci 40: 65-73

10. Thornton A, Blackall P (1984) Serological classification of Australian isolates of Haemophilus paragallinarum. Aust Vet J 61: 251-253.

11. Ziani ZB, Iritani Y (1992) Serotyping of Haemophilus paragallinarum isolated in Malysia. J Vet Med Sci 54: 363-365.

12. Songer J, Post K (2005) Veterinary microbiology: bacterial and fungal agents of animal diseases. Aust Vet J 84: 438.

13. Blackall $P$ (2011) An update on the diagnosis and prevention of fowl cholera and infectious coryza. Clinical Microbiology Reviews 93: 1522-1533.

14. Poernomo S, Sutarma S, Rafiee M, Blackall $P$ (2000) Characterization of isolates of Haemophilus paragallinarum from Indonesia. Aust Vet J 78: 759762.

15. Blackall P (1999) Infectious coryza: overview of the disease and new diagnostic options. Clinical Microbiol Rev 12: 627-632.

16. Kume K, Sawata A, Nagaki T, Matsumoto M (1983) Serological classification of Haemophilus paragallinarum with a haemagllutinin system. J Clin Microbia 17: 958-964.

17. Roodt Y (2009) Towards unraveling the genome of Avibacterium paragallinarum. University of free state, Bleomfontein, South Africa.

18. Yamaguchi T, Blackall P, Yakigami Y, Iritani Y, Hayashi Y (1990) Pathogenicity and serovar-specific haemagglutinating antigens of Haemophilus paragallinarum serovar B strains. Avian Dis 34: 964-968.

19. Page L (1962) Haemophilus infection in chickens: characteristics of 12 Haemophilus isolates recovered from diseased chickens. Amer J Vet Res 23 85-95.

20. Kume K, Sawata A, Nakase Y (1980) Immunologic relationships between Page's and Sawata's serotype strains of Haemophilus paragallinarum. Amer J Vet Res 41: 757-760.

21. Chukiatsirin K, Chansiripornchai $N$ (2008) An outbreak of infectious coryza in a layer farm. J Thai vet Med Assoc 58: 98-107.

22. Chukiatsiri K, Sasipreeyajan J, Neramitmansuk W, Chansiripornchai N (2009) Efficacy of autogenous killed vaccine of Avibacterium paragallinarum. Avian Dis $53: 382-386$.

23. Abd El-Ghany W (2011) Evaluation of autogenous Avibacterium paragallinarum bacterins in chickens. Int J Poult Sci 10: 56-61.

24. Gordan R, Jordan F (1982) Poultry diseases. 2nd edn. London.

25. Neramitmansuk W, Neramitmansuk $P$, Tantichareunyod T, Trongwongsa $L$ 
Citation: Dereja IA, Hailemichael D (2017) Infectious Coryza in Jimma Backyard Chicken Farms: Clinical and Bacteriological Investigation. J Vet Sci Technol 8: 412. doi: 10.4172/2157-7579.1000412

Page 6 of 6

(1995) The study of local strain infectious coryza vaccine in chicken. J Thai Vet Med Assoc 46: 53-60.

26. Iritani Y, Katagri K, Arita H (1980) Purification and properties of Haemophilus paragallinarum haemagllutinin. Amer J Vet Res 41: 2114-2118.

27. Marquez V, Marquez A, Caballero J, Lugo G, Cruz C, et al (2008) Secreted proteins of Avibacterium paragallinarum are lethal for chicken embryo. Anim Biodivers Emerg Dis 1149: 380-383.

28. Quinn P, Markey B, Carter M, Donnelly W, Leonard F (2002) Vet Microbio Microb Dis. Wiley-Blackwell.

29. Satary G, Rao P (2006) Veterinary pathology. 7th edn. JS Offset Printers Delhi, USA.

30. Vagas E, Terzolo H (2004) Epizootiology, prevention and control of infectious coryza. Vet Mex, p:35.

31. Bland M, Bickford A, Charlton B, Cooper G, Sommer F, et al. (2002) Case report: a sever infectious coryza infection in multi age layer complex in central California. Proceedings of the XXVII convention annual ANECA and $51^{\text {st }}$ western poultry diseases conference. Puerto Vallarta (Jalisco), Mexico.

32. Chukiatsirin K, Chotinun S, Chansiripornchai N (2010) An outbreak of Avibacterium paragallinarum serovar $B$ in a Thai layer farm. Thai $\mathrm{J}$ Vet Med 40: 441-444.

33. Welcham D, King S, Wragg P (2010) Infectious coryza in chickens in Great Britain. Vet. Record 167: 912-913.

34. Sonajya E, Swan S (2004) Small scale poultry production technical guide. FAO, Rome, Italy.

35. Sandoval V, Terzolo H, Blackall P (1994) Complicated infectious coryza outbreaks in Argentina. Avian Dis. 38: 672-678.

36. Hobb R, Tseng H, Downess J, Terry T, Blackall P, et al. (2002) Molecula analysis of a haemagglutinin of Haemophilus paragallinarum. Microbiology 184: $2171-2179$

37. Rimler R, Davis R, Page R, Kleven S (1978) Infectious coryza: preventing complicated coryza with Haemophilus gallinarum and Mycoplasma gallisepticum bacterins. Avian Dis 22: 140-150.

38. Jacobs A, Vanderberg K, Malo A (2003) Efficacy of new tetravalent coryza vaccine against emerging variant type B strains. Avian Pathol 32: 265-269.
39. Thrusfield M (2005) Veterinary epidemiology. 3rd edn. Blackwell, Berlin Germany.

40. Salle A (2002) Fundamental principles of microbiology. 21st edn. TMH Publishing Company Ltd., New Delhi, India.

41. Byarugaba D, Minga U, Gwakisa P, Katunguka E, Bisgaard M, et al. (2007) Investigation of occurrence of Avibacterium paragallinarum infections in Uganda. Avian Diseases 51: 534-539.

42. Mustefa M, Ali S (2005) Prevalence of infectious diseases in local and fayoum breeds of rural poultry (Gallus domesticus). Punjab Univ J Zool 20: 177-180.

43. Rahman M, Rahman A, Islam M (2009) Bacterial disease of poultry prevailing in Bangladesh. Res J Poult Sci 1: 1-6.

44. Islam M, Das B, Hossain K, Lucky N, Mostafa M (2003) A study on occurrence of poultry diseases in Sylhet region of Bangladesh. Int J Poult Sci 2: 354-356.

45. Azage T, Birhanu G, Hoekstra D (2010) Livestock impact supply and service provision in Ethiopia: challenges and opportunities for market oriented development. ILRI.

46. Shewantasew M (2010) Assessment of biosecurity situation and practices in live poultry markets of Addis Ababa. Jimma, Ethiopia.

47. Sakamato R, Sakai T, Ushijima T, Imamura T, Kino Y, et al. (2012) Development of an Enzyme-linked immunosorbent assay for the measurement of antibodies against infectious coryza vaccine. Avian Dis 56: 65-72.

48. Bragg R, Rensburg P, Heerden E, Albertyn J (2004) The testing and modification of a commercially available transport medium for transportation of pure cultures of Haemophilus paragallinarum for serotyping. Onderstepoort J Vet Res 71: 93-98.

49. Bragg R (2005) Effects of virulence of different serovars of Haemophilus paragallinarum on perceived vaccine efficacy. Onderstepoort J Vet Res 72: 1-6.

50. Davison F, Kaspers P, Schat K (2008) Avian immunology, London.

51. Thitisak W, Janviriyansopak O, Morrisur S, Srihakim S, Krueder R (1988) Causes of death foundation on epidemiological study of native chickens in Thai villages. Proceedings of the $5^{\text {th }}$ international symposium on veterinary epidemiology and economics. 